\title{
Issues in defining and measuring veteran community reintegration: Proceedings of the Working Group on Community Reintegration, VA Rehabilitation Outcomes Conference, Miami, Florida
}

\author{
Linda Resnik, PT, PhD; ${ }^{1-2 *}$ Daniel W. Bradford, MD, MPH; ${ }^{3-4}$ Shirley M. Glynn, PhD; ${ }^{5-6}$ Alan M. Jette, PT, PhD; ${ }^{7}$ \\ Caitlin Johnson Hernandez, $\mathbf{M S}^{\mathbf{8}}$ Sharon Wills, $\mathbf{P h D}^{\mathbf{9 - 1 0}}$ \\ ${ }^{1}$ Providence Department of Veterans Affairs (VA) Medical Center, Providence, RI; ${ }^{2}$ Department of Community Health, \\ Public Health Program, Brown University, Providence, RI; ${ }^{3}$ Psychosocial Rehabilitation and Recovery Center, \\ Durham VA Medical Center, Durham, NC; ${ }^{4}$ Duke University Hospital, Durham, NC; ${ }^{5}$ VA Greater Los Angeles Health- \\ care System, West Los Angeles Medical Center, Los Angeles, CA; ${ }^{6}$ Jane and Terry Semel Institute for Neuroscience and \\ Human Behavior, University of California Los Angeles Health System School of Medicine, Los Angeles, CA; ${ }^{7}$ Health \& \\ Disability Research Institute, Boston University School of Public Health, Boston, MA; ${ }^{8}$ Department of Psychology, \\ Texas A\&M University, College Station, TX; ${ }^{9}$ Center for Trauma Recovery, Posttraumatic Stress Disorder Clinical \\ Team, Austin Outpatient Clinic, Central Texas Veterans Health Care System, Austin, TX; ${ }^{10}$ Texas A\&M Health Science \\ Center School of Medicine, Bryan, TX
}

\begin{abstract}
In January 2010, the Department of Veterans Affairs (VA) Rehabilitation Research and Development Service convened a State of the Art (SOTA) conference to advance the field of outcome measurement for rehabilitation-related studies. This article reports on the proceedings of the SOTA Working Group on Community Reintegration. We explored the use of the International Classification of Health, Disability, and Functioning as a theoretical framework for measuring community reintegration; identified key dimensions of community reintegration that could and/or should be measured; discussed challenges in measuring community reintegration; suggested steps to enhance community reintegration measurement; proposed future research that focuses on outcomes measures for community reintegration and the study of community reintegration outcomes; and made policy recommendations that would facilitate community reintegration research within the VA.
\end{abstract}

Key words: community integration; community reintegration; disability evaluation; International Classification of Health, Disability, and Functioning; measurement; OIF/OEF; outcome assessment; role functioning; social functioning; veteran.
Abbreviations: CIQ = Community Integration Questionnaire; CRIS = Community Reintegration for Servicemembers; HSR\&D = Health Services Research and Development; ICF = International Classification of Functioning Disability, and Health; IOM = Institute of Medicine; IRB = institutional review board; IT = information technology; $\mathrm{NIH}=$ National Institutes of Health; OEF = Operation Enduring Freedom; OIF = Operation Iraqi Freedom; PROMIS = Patient-Reported Outcomes Measurement Information System; PTSD = posttraumatic stress disorder; RR\&D = Rehabilitation Research and Development; SCI = spinal cord injury; SOTA = State of the Art; TBI = traumatic brain injury; VA = Department of Veterans Affairs; VERA = Veterans Equitable Resource Allocation; VHA = Veterans Health Administration; WHO = World Health Organization. *Address all correspondence to Linda Resnik, PT, PhD; Providence VA Medical Center, 830 Chalkstone Ave, Providence, RI 02908; 401-273-7100, ext 2368.

Email: Linda.Resnik@va.gov

http://dx.doi.org/10.1682/JRRD.2010.06.0107 


\section{INTRODUCTION}

The recent conflicts in Iraq and Afghanistan (Operation Iraqi Freedom [OIF]/Operation Enduring Freedom [OEF]) have resulted in hundreds of thousands of new veterans to the Department of Veterans Affairs (VA) healthcare system. Although only 31,800 U.S. troops have been reported as wounded in OIF/OEF as of May 2010 [1], more than 790,000 veterans (of the more than 2 million deployed from 2001 to 2010) are ultimately expected to seek disability benefits for OIF/OEF servicerelated health problems [2].

Recent studies of OIF/OEF veterans report a high prevalence of psychological problems related to posttraumatic stress disorder (PTSD), anxiety, major depression, and mild traumatic brain injury (TBI) [2-5]. Although we are unaware of any published research to date, reports from media [6] and advocacy groups [7] suggest that servicemembers returning from OIF/OEF are at an increased risk for a wide range of problems when returning to community life, including marital and financial difficulties, problems with alcohol or substance abuse, homelessness, and motor vehicle accidents. From 2005 to 2009, the VA identified almost 3,000 OIF/OEF veterans who were homeless [8].

Both psychological and physical injuries can interfere with the veteran's experience of returning home and reuniting with family and community after combat. A recent survey of OIF/OEF veterans seeking VA care reported widespread prevalence of severe problems related to social functioning. For example, 49 percent of veterans reported problems participating in community activities, 42 percent in getting along with spouse or partner, and 25 percent in finding and keeping a job [9]. Other problems reported by OIF/OEF veterans in the survey included difficulty in controlling anger (52\%), loss of a job (24\%), dangerous driving (35\%), and legal problems (20\%) [9].

A widespread concern is that this new cohort of veterans will follow a similar path as Vietnam war veterans, of which a high proportion experience chronic PTSD and chronic, pervasive everyday life difficulties, including marital and work difficulties, poor parenting skills, violent behavior, alcohol and drug abuse, involvement with the criminal justice system, suicide attempts, and homelessness [10-13].

Helping this new cohort of combat veterans adjust to life at home and in the community and returning to participation in major social life roles is a VA priority. Par- ticipation in life roles has also been labeled "community integration" and return to participation in life roles as “community reintegration.” Reintegration is also an appropriate term to use with veterans who are returning from deployment in the military. The term reintegration has been used in the context of discharge from an institution such as a hospital, prison, or other setting in which the individual is separated from normal community living and returns to community life. The term reintegration is also appropriate when discussing cultural adaptation when repatriating from a foreign country [14].

The literature has considerable gaps regarding community integration and its measurement, both in the general population and among veterans. Measurement of community (re)integration is important in promoting the development of interventions that specifically target enhanced participation, assessing such treatments, documenting program effectiveness, and tracking population health in terms of involvement with (vs disengagement from) adult life roles.

The leadership of VA Rehabilitation Research and Development (RR\&D) Service recognizes that concentrated efforts are needed to advance the science of measurement of community reintegration. In late January 2010, RR\&D Service convened a State of the Art (SOTA) conference in Miami, Florida, with the purpose of advancing the field of outcome measurement for rehabilitationrelated studies. VA and non-VA experts from the areas of mental health, spinal cord injury (SCI), TBI, limb loss, vocational reintegration, community reintegration, and alternative research designs for rehabilitation research were invited to participate. The SOTA Working Group on Community Reintegration was asked to consider a theoretical framework for measuring community reintegration, evaluate the body of knowledge on measurement of community integration outcomes, identify measures that need to be developed, and make recommendations for future research and policy.

Grounded in members' research experience and knowledge of and review of the existing literature, this article summarizes the proceedings of the SOTA Working Group on Community Reintegration. This article (1) explores the use of the International Classification of Health, Disability, and Functioning (ICF) as a theoretical framework for measuring community reintegration; (2) identifies key dimensions of community reintegration that could and/or should be measured; (3) discusses challenges in measurement of community reintegration; (4) suggest steps to enhance 
community reintegration measurement; (5) proposes future research that focuses on outcomes measures for community reintegration and the study of community reintegration outcomes; and (6) makes policy recommendations that would facilitate community reintegration research within the VA.

\section{THEORETICAL APPROACH TO DEFINING COMMUNITY REINTEGRATION}

The specific aspects and elements of life that could potentially be incorporated into the assessment of community reintegration are multifaceted, with no gold standard of the elements applicable to all persons [15-16]. Adult life roles are culturally defined and vary by life stage, but existing measures of community reintegration typically consider engagement in diverse aspects of role functioning as an (1) independent, autonomous person; (2) family member; (3) friend; (4) spouse and/or intimate partner; (5) parent; (6) civic and community member; (7) student; and (8) member of the workforce.

We agreed that the participation domain as defined by the ICF offered a theoretically sound method of framing community integration and defining key components. The ICF is a classification system developed by the World Health Organization (WHO) to record and organize a wide range of information about health and healthrelated states that complements information already available within the WHO International Classification of Diseases-10. The ICF classification includes information on the functioning of individuals in terms of their body functions and structures, activities, and participation in important life roles [17-18].

The overall purpose of the ICF is to provide a standard language and framework for the description of human functioning and its negative notion: disability. The ICF is divided into two components. The first covers functioning at four levels: (1) body function, (2) body structure, (3) activities, and (4) participation. The second component covers factors that comprise the context for functioning, including environmental and personal factors. We recommended that items measuring elements of role functioning (defined earlier) be adopted from the ICF chapters on activities and participation because the domain of participation focuses on the person's involvement in society (i.e., community integration).

The SOTA Working Group on Community Reintegration identified key dimensions of participation appli- cable to veterans, including the following types of role participation:

- Social: engaging with friends and family members.

- Work: engaging in paid and unpaid employment.

- Education: engaging in learning activities.

- Parental: caring for and supervising the raising of children.

- Spouse/significant other: engaging in a long-term relationship.

- Spiritual/religious: engaging in activities that address spiritual needs.

- Leisure: engaging in preferred avocational activities.

- Domestic life: engaging in activities to maintain the home and live in a noninstitutional residence within the community.

- Civic: engaging in activities focused on the betterment of society and the responsibilities of citizens.

- Self-care: engaging in activities to maintain societal standards of grooming and to maintain health.

- Economic life: engaging in simple and complex economic transactions and having command over economic resources.

Participation in some of these role functions occurs in interaction with other people, while other roles may be performed without social interaction.

\section{CHALLENGES IN MEASUREMENT OF COMMUNITY REINTEGRATION}

\section{No Gold Standard}

Measuring the domain of participation is a relatively new field [19]. In the ICF taxonomy, the term participation replaces the term disability used in 1991 and 1997 Institute of Medicine (IOM) models and the Nagi model of disability [20], as well as the term handicap used in the IOM's 1980 model [19]. These earlier models have guided the development of most, but not all, disability outcomes measures [21]. Because the content and theoretical underpinning of measures of disability and handicap vary widely, community integration instruments may or may not have items related to the construct of participation as defined by the ICF.

Currently, no accepted gold standard measure against which other measures can be compared exists and no universally accepted agreement exists on the specific content areas that are most meaningful for use in assessing 
community reintegration of veterans. Some populationspecific measures have been developed, for example, for those who have experienced stroke, SCI, or TBI [22-24]. Only one community integration measure, the Community Reintegration for Servicemembers (CRIS), has been designed to incorporate issues specific to injured servicemembers as identified by formative research with veterans, caregivers, and clinicians. The recently developed CRIS instrument uses the theoretical framework of the ICF as described earlier, measures objective and subjective elements of participation, and includes items related to negative as well as positive aspects of participation [25]. Preliminary studies have demonstrated the reliability and validity of the measure, and several ongoing research projects currently use it.

\section{Distinguishing Between Activities and Participation}

Another challenge to measuring participation is the overlap between the constructs of activities and participation. In the ICF framework, the domains of body functions and structure, activities, and participation are presented as distinct from one another. In fact, the graphic model of the ICF shows the concepts of activity and participation as two completely separate domains [17-18]. However, the ICF taxonomy, which is the language used to describe each aspect of functioning, uses a single coding structure for both activity and participation. For example, the Activities and Participation chapter on Major Life Areas includes all aspects of work and employment. The ICF taxonomy for activity and participation includes nine chapters: Learning and Applying Knowledge; General Tasks and Demands; Communication; Mobility; Self-Care; Domestic Life; Interpersonal Interactions and Relationships; Major Life Areas; and Community, Social, and Civic Life. The ICF taxonomy includes second, third, and fourth level coding within each chapter of the taxonomy, with each level of coding becoming increasingly specific.

Despite the single taxonomy, according to the ICF, the domains of activities and participation are thought to be conceptually distinct. Activities focus on the person's individual functioning and are more likely to be performed alone [19]. In contrast, participation focuses on the person's involvement in society (i.e., social functioning) and would more likely be performed with others. However, activities such as shopping or traveling, which are critical aspects of community (re)integration, might be undertaken alone but could arguably be considered aspects of participation. An ongoing debate exists on whether these domains are conceptually distinct and, if so, how to distinguish between them [26].

\section{Measurement Approaches}

Measuring participation can take a variety of approaches. For example, measures may assess subjective as well as objective aspects of participation. Objective approaches assess quantity of participation (i.e., frequency, intensity, and amount and use of assistive device or other type of help), whereas subjective approaches assess quality and type (i.e., perceived difficulty, limitations, and autonomy, as well as satisfaction with participation) [27]. Several studies show that frequency and intensity of activities are only weakly and inconsistently associated with expressed satisfaction with the level of participation with these activities [27-31]. Commonly used measures, such as the Community Integration Questionnaire (CIQ) [32] and the Craig Handicap Assessment and Reporting Technique [33], are objective measures that assess elements of participation. These are scored based on normative standards with the underlying assumption that "more is better" [34] and that independent performance of an activity is preferable to receiving assistance [35]. A limitation of objective measures is that they fail to consider individual preferences, personal choices, and values by measuring satisfaction with extent of participation [30-31,36]. In the CIQ, for example, frequency of participation in activities and completing activities independently (i.e., without assistance) is reflected in the final score [32]. In some measures, an individual's participation is compared with that of a person without a disability and is evaluated from a societal perspective [29]. However, community integration must also be understood in terms of the "insider's" perceptions and experience [37], and thus, the assessment of subjective perceptions, including perceived limitations and satisfaction with participation, are critical. Table 1 shows that the approach to measurement of selected measures of participation varies. It compares the approaches used in a selection of some of the most recently developed measures of participation: CRIS [25], National Institutes of Health (NIH) Patient-Reported Outcomes Measurement Information System (PROMIS) social function scale [38], and Community Participation Index [15].

Additional approaches to measuring community reintegration outcomes include assessing facilitators of or barriers to participation. These types of assessment tools evaluate resources within the environment, such as use of products and technology and social support and access to 
Table 1.

Examples of approaches to assessment of participation in three newer measures.

\begin{tabular}{lccccc}
\hline Measure & Frequency Difficulty & $\begin{array}{c}\text { Effect/ } \\
\text { Extent of } \\
\text { Disruption }\end{array}$ & $\begin{array}{c}\text { Perceived } \\
\text { Limitations }\end{array}$ & Satisfaction \\
\hline CRIS [1] & $\mathrm{X}$ & - & - & $\mathrm{X}$ & $\mathrm{X}$ \\
CPI [2] & $\mathrm{X}$ & - & - & $\mathrm{X}$ & $\mathrm{X}$ \\
PROMIS [3] & - & - & - & - & $\mathrm{X}$
\end{tabular}

1. Resnik L, Plow M, Jette A. Development of the CRIS: A measure of community reintegration of injured services members. J Rehabil Res Dev. 2009; 46(4):469-80. [PMID: 19882482]

http://dx.doi.org/10.1682/JRRD.2008.07.0082

2. Hammel J, Magasi S, Heinemann A, Whiteneck G, Bogner J, Rodriguez E. What does participation mean? An insider perspective from people with disabilities. Disabil Rehabil. 2008;30(19):1445-60. [PMID: 18923977] http://dx.doi.org/10.1080/09638280701625534

3. Cella D, Yount S, Rothrock N, Gershon R, Cook K, Reeve B, Ader D, Fries JF, Bruce B, Rose M; PROMIS Cooperative Group. The Patient-Reported Outcomes Measurement Information System (PROMIS): Progress of an NIH roadmap cooperative group during its first two years. Med Care. 2007; 45(5 Suppl):S3-S11. [PMID: 17443116]

http://dx.doi.org/10.1097/01.mlr.0000258615.42478.55

CPI = Community Participation Index, CRIS = Community Reintegration for Servicemembers, PROMIS = Patient-Reported Outcomes Measurement Information System.

social security services, assistance programs, and health services. Data on these elements may help explain role functioning. Several environmental measures have recently been developed. One promising measure is the Craig Hospital Inventory of Environmental Factors, which assesses five dimensions of environment barriers: (1) attitudes and support, (2) services and assistance, (3) physical and structural, (4) policy, and (5) work and school [39]. We are unaware of any prior research on the role of the environment and community reintegration of combat veterans. However, we believe, as do others, that barriers or facilitators in the environment may greatly affect participation, with an effect that is potentially greater than underlying physiological and structural impairments [40].

\section{Challenges in Assessing Community Reintegration Outcomes in Persons with Mental Health Conditions}

Community reintegration is inherent in the definition of recovery proposed by the President's New Freedom Commission on Mental Health, "Recovery refers to the process in which people are able to live, work, learn and participate fully in their communities" [41]. While recovery includes the notion of community reintegration, several factors may complicate progress toward this goal among persons with psychiatric illnesses. First, persons with psychiatric illnesses may find the goal of pursuing community reintegration daunting and may be reluctant to set a goal of further integration into the community because of their current symptom levels. For example, veterans with PTSD or depression may prefer isolation even if social contact is integral to community integration. Here, pursuing a personal goal and the tenets of community reintegration may collide. Many of the evidence-based psychological treatments currently supported by the VA (i.e., cognitive processing therapy, prolonged exposure therapy, cognitive-behavior therapy) actively address and help to modify avoidant behaviors, progressively enabling the individual to move toward increasingly more productive social roles. Measurement of community reintegration should be able to reflect these individuals' movement along the continuum of behaviors, from those that are maladaptive to those that reflect more adaptive social functioning as a consequence of treatment.

We observed that the VA has not, until recently, focused attention on the bidirectional influence of the family context on the veteran. For example, it is only with the recent dissemination of the Uniform Mental Health Services Package that VA mental health clinicians are now directed to have at least yearly conversations with veterans about involving their families in care [42]. We asserted that for many veterans, successful community reintegration will require reconciliation between family and veteran expectations. For example, many combat veterans return from war zone deployments with a sense of alienation from the families and communities they are returning to, with little hope that they will ever again "fit in" with the society they left. The family and community, on the other hand, expect that the veteran will re-adapt to community norms and expectations. Successful community reintegration will depend on how effectively the gaps between this alienation and the community's expectations can be bridged. Ideally, additional measures could be developed that would assess family and community perspectives so as to quantify the degree to which these gaps are reconciled.

\section{Measurement of Community Integration Across Lifespan}

The Veterans Health Administration (VHA) serves a diverse group of individuals, varying in terms of age, combat exposure, diagnosis, chronicity of illness and injury, and timing of the onset of an illness or occurrence of an injury across the lifespan. The concept of community 
reintegration varies substantially in meaning among individuals within this diverse group. For some, it may mean a return to the level of functioning and integration into the community that was experienced before military entry or the onset of an illness. In that sense, the term community reintegration is a fairly intuitive and clear concept. Helping others integrate into the community, particularly veterans who entered the military at a young age and are returning to civilian life and VHA care in their late teens or early 20s, involves accomplishing developmental milestones and assuming societal roles that may not have been established prior to military service. Further, preferences for the types of valued life roles that an individual wishes to assume vary across the lifespan. For example, younger veterans may be embarking on a career, buying a home, and supporting a family, while older veterans may be retiring, moving to assisted living facilities, and assuming new roles with respect to family members. For these reasons, the types of measures used to assess community reintegration, the settings where the measures are delivered, and the meaning of the information gathered could vary within the population of veterans served by VHA.

Improving the measurement of community reintegration will require a systematic effort to address variations in role functioning of veterans across their lifespan, covering a continuum from initial entry into the military to deployment, returning home, redeployment, and retirement.

\section{FIRST STEPS TO MEASUREMENT OF COMMUNITY REINTEGRATION IN VETERANS}

We suggested a process to advance the measurement of community reintegration in veterans. This process should begin by identifying key aspects of community reintegration or elements that should be measured. Key elements should consider the role function specific to veterans and military servicemembers across the life span. Once core elements are identified, existing measures can be mapped to this core set to understand the content and coverage of existing measurement tools. New tools or items for existing measures can be developed to fill any identified gaps.

\section{Identifying Core Group of Elements to Assess Community Reintegration}

To advance the understanding of treatment outcomes and permit description of different patient subtypes, the
VA clinical and research communities would benefit from a clear vision of the elements needed to measure community reintegration and the identification of a core group of standardized items, a "minimum data set" on community reintegration that could be adopted as part of the VA health information and electronic medical record system and used by clinicians, administrators, and researchers. Identifying secondary core sets for subsets of the veteran population may also be beneficial. Several approaches to identifying core sets exist. One way to develop a minimum data set for community reintegration would be to adopt an approach to developing core sets of measurement items, such as was done for the ICF. Using a global consensus process, the ICF classification was endorsed by the World Health Assembly in 2001 [17].

Understanding that a comprehensive classification such as the ICF, by its very nature, becomes very complex and cumbersome for daily use, the WHO undertook the ICF Core Sets project [43]. Acknowledging that clinicians and researchers might need only a fraction of the categories found in the ICF to characterize a particular clinical condition or disorder, the ICF Core Sets project identified core sets of ICF items for select clinical conditions employing a rigorous scientific process. The ICF Core Sets project involved a formal decision-making and consensus building process that integrated evidence from preliminary studies and expert opinion. For each condition, the preliminary studies included a Delphi exercise that represented the expert view, a systematic review on outcomes used in research that represented the view of researchers, and an empirical data collection phase, using the ICF checklist to represent the view of patients undergoing healthcare treatment. Based on the information that emerged from these phases, the relevant ICF Core Sets were identified for each clinical condition. To date, core sets have been developed for a range of mental health and physical conditions. As examples, core sets have been developed for persons with sleep disorders [44], head and neck cancer [45], bipolar disorder [46], SCI [47], multiple sclerosis [48], stroke [49], depression [50], and obesity [51]. These represent the starting point for a subsequent formal decision-making process that took place in formal consensus conferences sponsored by the WHO. Elements of core sets can later be mapped to existing measures to guide measurement selection.

Other alternatives to the development of core sets involve less formal processes of identifying and validating instrument content through dialog with content experts and 
formative research with stakeholders [16]. Formative research, including qualitative research studies using a range of methodologies, is often used by instrument developers to ensure content validity. Qualitative research was used to inform the development of the CRIS measure [25].

Yet another alternative for developing community reintegration measures is to identify dimensions of veteran role functioning from research with veterans who demonstrate successful community integration. This approach may further our understanding of the dimensions of role functioning for veterans that could or should be measured. However, we are unaware of research that has taken this approach.

\section{Veteran/Military Role Function}

A key aspect of community integration is participation in socially constructed roles such as "worker," "parent," or "partner." In considering the elements of these varying roles, it is clear that the role functions of "Armed Forces member" and "veteran" have distinct attributes that are worthy of further investigation. Careful measurement of participation in these roles is precluded at this time by a lack of a detailed description of their elements. For example, while one could consider Armed Forces member an occupational role, distinctive requirements exist for the role (e.g., ability to accommodate living in a foreign country, willingness to sacrifice one's life if asked, and extreme physical agility) that are often not captured in traditional measures of occupational role functioning and yet are often critical to successful role performance.

Veteran role functioning is not typically addressed in measures of role functioning, and yet many who have served in the Armed Forces strongly identify with this role. In fact, our search of the literature did not yield any research that defined veteran role functioning. However, we agreed that items such as affiliation with other veterans and current Armed Forces members and strong allegiance to country are integral to the role. Veteran status is typically overlaid on other role functions (worker, partner, etc.), yet has distinctive elements. However, because of injuries, many veterans have incurred some level of difficulty in engagement pursuant to their involvement in the military and thus may be limited in their ability to meet other role functions adequately.

\section{Mapping Content of Existing Measures}

Once pertinent elements of the participation taxonomy are identified, understanding how existing measures map to these elements is critical. Based on these types of analyses, we may recognize that existing measures provide adequate coverage for some roles, or we may realize that new measures or adaptations to existing items are indicated. Several authors have performed extensive reviews of existing measures, linking each item to the ICF taxonomy to assess coverage of the construct of participation.

Because many questionnaires used to assess participation in life were developed using other models of disability [21], most fail to cover all nine domains of participation as identified by the ICF. Furthermore, existing measures cover different areas of content. Resnik and Plow, for example, found that very few of the 40 measures in their review of participation measures contained at least 1 item pertaining to each of the 9 domains defined in the ICF, and in many instances, single questions addressed more than 1 domain [52]. Table 2 shows the mapping of several newer participation measures, including the CRIS [25], the NIH PROMIS social function scale [38], and the Community Participation Index [15]. This analysis used methods similar to those described in a previous report with more complete analysis of other measures [52].

\section{FURTHER RESEARCH}

\section{Conducting Head to Head Instrument Comparisons}

The next step in advancing the measurement of community reintegration involves the application of specific psychometric criteria to the evaluation of new and existing measures of community reintegration to provide a basis for evaluating the utility of measurement approaches. Key psychometric criteria for measures include reliability, validity, and responsiveness to clinically meaningful change [53]. While a full discussion of these criteria and the approaches to investigating them is beyond the scope of this article, this type of research is critical for guiding the choice of measures for research and practice.

We need studies of measurement reliability to assess whether or not measures yield consistent results when used with veterans and are free from random sources of error. These types of studies are a necessary first step in measurement assessment, because a measure cannot have validity if it is not reliable.

Research is needed to validate new and existing community reintegration instruments by examining their content, construct, concurrent, and predictive validity. A challenge in designing construct validity studies is that a 
Table 2.

Comparison coding of three newer measures of participation.

\begin{tabular}{|c|c|c|c|}
\hline Code & $\begin{array}{c}\text { CRIS } \\
{[1]}\end{array}$ & $\begin{array}{l}\text { PROMIS } \\
{[2]}\end{array}$ & $\begin{array}{l}\text { CPI } \\
{[3]}\end{array}$ \\
\hline \multicolumn{4}{|l|}{ Interpersonal Interactions and Relationships } \\
\hline d710 Basic interpersonal interactions & $\mathrm{X}$ & $\mathrm{X}$ & $\mathrm{X}$ \\
\hline d720 Complex interpersonal interactions & $\mathrm{X}$ & - & $\mathrm{X}$ \\
\hline $\begin{array}{l}\text { d729 General interpersonal interactions, other } \\
\text { specified and unspecified }\end{array}$ & - & - & - \\
\hline d730 Relating with strangers & - & - & - \\
\hline d740 Formal relationships & $\mathrm{X}$ & - & $\mathrm{X}$ \\
\hline d7400 Relating with persons in authority & $\mathrm{X}$ & - & - \\
\hline d750 Informal social relationships & $\mathrm{X}$ & - & $\mathrm{X}$ \\
\hline d760 Family relationships & $\mathrm{X}$ & $\mathrm{X}$ & $\mathrm{X}$ \\
\hline d770 Intimate relationships & $\mathrm{X}$ & - & $\mathrm{X}$ \\
\hline \multicolumn{4}{|l|}{ Major Life Areas } \\
\hline d810 Informal education & - & - & - \\
\hline d815 Preschool education & 一 & - & - \\
\hline d820 School education & - & - & $\mathrm{X}$ \\
\hline d825 Vocational training & - & - & - \\
\hline d830 Higher education & - & - & - \\
\hline d839 Education, other specified and unspecified & - & - & - \\
\hline d840 Apprenticeship (work preparation) & - & - & - \\
\hline d840-859 Work and employment & $\mathrm{X}$ & - & - \\
\hline d845 Acquiring, keeping, and terminating a job & $\mathrm{X}$ & - & $\mathrm{X}$ \\
\hline d8450 Seeking employment & $\mathrm{X}$ & - & - \\
\hline d850 Remunerative employment & - & $\mathrm{X}$ & $\mathrm{X}$ \\
\hline d855 Non-remunerative employment & - & $\mathrm{X}$ & $\mathrm{X}$ \\
\hline $\begin{array}{l}\text { d859 Work and employment, other specified and } \\
\text { unspecified }\end{array}$ & - & - & - \\
\hline d860 Basic economic transactions & - & - & - \\
\hline d865 Complex economic transactions & - & - & - \\
\hline d870 Economic self-sufficiency & $\mathrm{X}$ & - & - \\
\hline $\begin{array}{l}\text { d879 Economic life, other specified and } \\
\text { unspecified }\end{array}$ & - & - & - \\
\hline \multicolumn{4}{|c|}{$\begin{array}{l}\text { 1. Resnik L, Plow M, Jette A. Development of the CRIS: A measure of com- } \\
\text { munity reintegration of injured services members. J Rehabil Res Dev. } \\
\text { 2009;46(4):469-80. [PMID: } 19882482] \\
\text { http://dx.doi.org/10.1682/JRRD.2008.07.0082 }\end{array}$} \\
\hline \multicolumn{4}{|c|}{$\begin{array}{l}\text { 2. Cella D, Yount S, Rothrock N, Gershon R, Cook K, Reeve B, Ader D, Fries } \\
\text { JF, Bruce B, Rose M; PROMIS Cooperative Group. The Patient-Reported } \\
\text { Outcomes Measurement Information System (PROMIS): Progress of an } \\
\text { NIH roadmap cooperative group during its first two years. Med Care. 2007; } \\
\text { 45(5 Suppl):S3-S11. [PMID: } 17443116] \\
\text { http://dx.doi.org/10.1097/01.mlr.0000258615.42478.55 }\end{array}$} \\
\hline \multicolumn{4}{|c|}{$\begin{array}{l}\text { 3. Hammel J, Magasi S, Heinemann A, Whiteneck G, Bogner J, Rodriguez E. } \\
\text { What does participation mean? An insider perspective from people with dis- } \\
\text { abilities. Disabil Rehabil. 2008;30(19):1445-60. [PMID: 18923977] } \\
\text { http://dx.doi.org/10.1080/09638280701625534 }\end{array}$} \\
\hline $\begin{array}{l}\text { CPI = Community Participation Index, CRIS = C } \\
\text { Servicemembers, PROMIS = Patient-Reported Ot } \\
\text { mation System. }\end{array}$ & Sommun & ity Reintegr & $\begin{array}{l}\text { tion for } \\
\text { t Infor- }\end{array}$ \\
\hline
\end{tabular}

gold standard is not available to define the construct. Researchers must carefully choose those health- and nonhealth-related measures that they believe are related to the underlying construct being assessed. The demonstration of a predicted pattern of correlations (convergence and discrimination) of a community reintegration measure with other independent measures would demonstrate evidence of the measure's construct validity. We need studies of predictive validity to determine whether a measure can be used as a prognostic indicator to predict or forecast a future event or criterion.

Measures may be reliable and demonstrate good content, construct, and predictive validity, but not be sufficiently sensitive to detect important change [54], thus severely limiting the usefulness for research or clinical practice. We need several different types of research approaches to examine the responsiveness to change of community reintegration measures. Studies of responsiveness can include examination of distribution-based statistics to estimate statistics such as effect size, standard error of measurement, and minimal detectable change and use of anchor-based approaches to assess a measure's diagnostic or predictive performance.

\section{Expanding the Scope of Measurement: Effect on Society}

Our operationalization of community integration is grounded in the participation domain of the ICF. Within this framework, we understand community integration to occur within a social context-that is, many of the behaviors involved in being a worker, student, intimate partner, or parent require interaction with other persons as a key component of fulfilling that role.

It is well known in mental health research that negative family attitudes play a key role in community reintegration insofar as they effect community tenure itself [55]. Furthermore, the affect of caregiving is increasingly recognized in key supporters of persons with TBI [56] and SCI [57]. For many individuals confronting significant mental or physical health challenges, dependence on supporters to provide some level of assistance and accommodation to promote successful community adjustment is a critical aspect of long-term recovery.

While no current measure exists as the gold standard to assess community integration, many extant measures of social and community functioning incorporate items assessing this interactional aspect of the role. An often under attended to aspect of measurement of community integration is the effect of those efforts of integration on the other key supporters involved in these interactions - conjugal (like) partners, kin, friends, and employers. Observations from these key supporters are sometimes used to corroborate functioning reports made by the individual being assessed (for example, on the Social Adjustment Scale 
Family [58]). A measure that assesses the perspectives, burdens, gratifications, stigma, and assistance involved in supporting the community integration of another could provide additional meaningful information. Such a measure could also assess the positive contributions of the individual pursuing community integration to the relationship with the key supporter

Routine assessment of supporters' attitudes and experiences concerning the person pursing community integration may both help identify persons at risk for poor integration as well as guide the development of supporter-involved interventions to promote better community integration. For example, family-based interventions incorporating structured training on problem-solving have been found to reduce relapse in schizophrenia [59-61] and bipolar disorder [62-63], as well as reduce depression and healthcare complaints in caretakers of persons with TBI [64].

\section{ADVANCING COMMUNITY REINTEGRATION MEASUREMENT WITHIN VA}

We recognized the critical importance of using community reintegration measures as key outcome assessment tools. We recommended further research to evaluate existing measures and develop new measures as needed and identified barriers to the conduct of research on community reintegration and measurement in the VA. We suggested systems changes to decrease the breadth and depth of barriers to research so that the VA could best serve the needs of patients and society. We identified barriers to intramural and extramural research collaborations and the involvement of clinicians in this research. We also noted a need for greater measurement expertise within the VA.

\section{Funding Research on Community Reintegration}

VA research funding comes from different streams. Although measurement of community reintegration is highly relevant to VA RR\&D, researchers with an interest in measurement and methodology have historically been supported by VA Health Services Research and Development (HSR\&D) funding. Many VA researchers are located within HSR\&D centers of one type or another. Continued funding of HSR\&D centers is often contingent upon the number and quality of HSR\&D-funded research projects among center investigators. Thus, disincentives exist for HSR\&D researchers to work on rehabilitation-related topics or seek grant support from another VA agency such as RR\&D.
It may be beneficial for VA Central Offices of Research in all divisions to revisit their criteria for successful VA centers to encourage collaboration across research divisions. One mechanism that may be helpful is for HSR\&D and RR\&D to jointly fund research projects on measurement of community reintegration, thus allowing "credit" to be given for HSR\&D centers and thereby removing negative disincentives.

\section{Multisite Collaborations}

Research on community reintegration measures would be facilitated if we were able to collect data from large numbers of veterans from VA medical centers across the country. Data collection at multiple sites would enable speedier accrual of data, including a more diverse patient population. However, most multisite collaborative research efforts are time consuming and burdensome, using increased physical, financial, and personnel resources to navigate the policies at each site.

Varying institutional review board (IRB) requirements at each VA medical center slow these types of efforts as researchers work to meet unique site requirements and submit their protocols to multiple human subjects' protection reviews. Fortunately, this process has the potential to be expedited with the Central IRB office. However, Central IRB is relatively new and most protocols do not go through this process.

We recommend creating a new RR\&D Center of Measurement Excellence that would coordinate the collection of rehabilitation outcomes measures across sites. This center would provide a network for multisite data collaboration that could be sustained over time. By employing a central IRB procedure and facilitating the use of multiple resources across participating sites, this center could potentially advance necessary research opportunities in a more timely, cost-efficient, and practical manner.

The need to assess community reintegration is evident inside the VA, but it is also a growing priority in the nonVA community. The measures of community reintegration and approaches to measurement of community reintegration might be advanced more quickly with collaborative activities that leverage the strength of VA and non-VA researchers. Research on community reintegration would also be facilitated by efforts to collect data from institutions outside of the VA (such as military hospitals and/or civilian rehabilitation centers). These types of interagency collaborations present many challenges because of multiple IRBs from different institutions and strict policies on data 
sharing. While obvious fruitful potential collaborations could occur between VA researchers and existing nonVA researchers and Centers of Excellence in Rehabilitation Outcome Measures, significant challenges to realizing such collaborative activities exist. VA and non-VA researchers alike have expressed frustration at the challenges of collaborating across institutions. Restrictions on data access and data sharing and difficulty in VA-associated nonprofits administering NIH or other funding either directly or through subcontracts with affiliated universities further exacerbate these challenges.

\section{Building Measurement Resources}

VA researchers, clinicians, and administrators are interested in conducting research to obtain evidence about patient status, treatment effectiveness, program effectiveness, and quality performance. Many grassroots efforts are hampered because of lack of expertise in selecting and utilizing appropriate outcome measures. Further, access to biostatisticians or psychometricians with the statistical expertise to assist in analysis is limited in many VAs. The VA system as a whole may benefit from the creation of a resource center for measurement. Such a center would ideally provide expertise on specific functional measures such as measures of cognitive and motor function, as well as on broader functional measures such as measures of community reintegration.

\section{Involving Clinicians in Community Reintegration Research}

In the present funding mechanisms available in VA for project grants, salary for physicians and nurses cannot be included in budget proposals. This creates an obvious barrier to the participation of these professionals in VA research projects, because negotiating release time from clinical duties is difficult when no immediate dedicated funds to hire replacements for those duties exist. One-to-one matching of VA research budget direct costs with indirect costs paid directly to the medical center (through Veterans Equitable Resource Allocation [VERA] monies) does create a substantial financial incentive for research projects and may, to some extent, even mitigate the financial disincentive for participation by physicians and nurses. However, in the current method of disbursement of indirect costs through the VERA process, payment to the medical centers is delayed by several years. Furthermore, no guarantee exists that VERA dollars will be used by the medical center to support research activities or infrastructure. VA policies for research project budgets and disbursement of indirect costs should be reevaluated to improve the pace of advances in our understanding of community reintegration and to assure the inclusion of a diverse group of relevant professionals in these efforts.

\section{Using Information Technology}

Information security is an important priority throughout the VA. With VA databases containing Social Security numbers, addresses, and detailed health and military records of millions of individuals who have served in the U.S. Armed Forces, the potential harm to veterans that could result from these records being obtained and used for fraudulent or stigmatizing purposes is substantial, in addition to simply the breach of confidentiality involved in such an occurrence. For these reasons, the VA has developed rigorous methods for assuring information security, including requiring that procurement of information technology (IT) equipment being delegated to one central entity, Information Resources Management.

Access by veterans to VA computers has been limited to a modest number of workstations used primarily to access My HealtheVet. This organizational structure and restriction of access to computers can create barriers for VA researchers in obtaining needed IT equipment for research projects, as well as to the ways that computers can be used in research efforts. For example, a self-report community reintegration measure developed with funding by VA HSR\&D is the CRIS, mentioned earlier. With a total item pool of over 300 items, the use of a computer adaptive test called the CRIS-CAT is needed to reduce the veteran response burden. Current IT polices include significant barriers to providing computers that can be used directly by veterans to respond to computer adaptive tests like the CRIS-CAT.

In addition to the barriers that current IT policies present for research on community reintegration, these policies also create barriers to those veterans using VHA services to try to integrate into the community. In current clinical programs, availability of computers to veterans for the purposes of learning new skills, developing résumés for employment, and other important uses of computers expected of adults are limited. For these reasons, we recommend that VA policies for the use and procurement of IT-related equipment be reviewed and improved to facilitate timely access to IT equipment by researchers and veterans for measurements that involve self-report. 


\section{CONCLUSIONS}

While VA medical centers provide some acute care, many veterans receive care for more chronic or disabling physical conditions or mental disorders. Common conditions include limb loss and/or damage or PTSD accruing from combat exposure and serious psychiatric disorders such as schizophrenia and bipolar illness, as well as the age-related ailments seen in our increasingly older veteran population. For these more enduring and disabling conditions, reintegration into the community is often a primary intervention goal. Measuring progress in meeting this goal across the range of disorders treated in VA has been elusive. In large part, this difficulty in measurement stems from lacking a consensual definition of successful community reintegration. As outlined in this article, specifying the universe of societal roles included in community living and identifying the behaviors involved in successful performance of these societal roles has proven to be a daunting task for both researchers and clinicians targeting reintegration goals. However, we believe that use of the lens of participation as defined by the ICF can serve as a springboard to guide future efforts.

Even with this framework, we expect that measuring community reintegration will continue to be challenging, because no one measure has been developed that incorporates every element of the participation domain outlined in the ICF. Even if such a tool did exist, it may be lengthy and burdensome to utilize. Therefore, we recommend greater efforts to identify critical elements of participation for specific groups of veterans, as well as efforts to increase the utility of measure implementation. Further scale development and refinement are needed, with research conducted to assure that all tools have sound psychometric properties. An example of this type of research is found in the development of the veteran-specific CRIS measure [25].

While its mission would seem to make the VA uniquely suited to the kinds of investigations necessary to develop measurement of community reintegration, in practice many challenges to conducting VA research exist that impede progress in this effort. If these can be successfully addressed, the VA has the potential to foster the development of strategies and tools that will greatly enhance the community reintegration of veterans. Furthermore, these efforts are likely to have dramatic effect on the larger community of impaired and disabled persons.

\section{ACKNOWLEDGMENTS}

\section{Author Contributions:}

Manuscript concept and design: L. Resnik, D. W. Bradford, S. M. Glynn, A. M. Jette, C. Johnson Hernandez, S. Wills.

Drafting of manuscript: L. Resnik, D. W. Bradford, S. M. Glynn,

A. M. Jette, C. Johnson Hernandez, S. Wills.

Critical revision of manuscript for important intellectual content:

L. Resnik, D. W. Bradford, S. M. Glynn, A. M. Jette, C. Johnson

Hernandez, S. Wills.

Administrative, technical, or material support: C. Johnson Hernandez. Financial Disclosures: The authors have declared that no competing interests exist.

Funding/Support: This material is the result of work supported by VA RR\&D.

Additional Contributions: The authors would like to acknowledge Margaret Brown, Assistant Clinical Professor, Department of Community Medicine, Mount Sinai School of Medicine, New York, New York, for her comments on the manuscript and participation in the SOTA Working Group on Community Reintegration discussion. Dr. Bradford is now with the Psychosocial Rehabilitation and Recovery Center, Durham VA Medical Center, and Department of Psychiatry and Behavioral Sciences, Duke University Medical Center. Ms. Johnson Hernandez is now with the Department of Educational Psychology, Texas A\&M University.

\section{REFERENCES}

1. Saban Center for Middle East Policy. Iraq index [Internet]. Washington (DC): Brookings Institute; 2011 [updated 2011 Sep 30; cited 2010 May 25]. Available from: http://www.brookings.edu/saban/iraq-index.aspx

2. Institute of Medicine. Returning home from Iraq and Afghanistan: Preliminary assessment of readjustment needs of veterans, service members, and their families. Washington (DC): National Academies Press; 2010.

3. Hoge CW, Auchterlonie JL, Milliken CS. Mental health problems, use of mental health services, and attrition from military service after returning from deployment to Iraq or Afghanistan. JAMA. 2006;295(9):1023-32. [PMID: 16507803] http://dx.doi.org/10.1001/jama.295.9.1023

4. Milliken CS, Auchterlonie JL, Hoge CW. Longitudinal assessment of mental health problems among active and reserve component soldiers returning from the Iraq war. JAMA. 2007;298(18):2141-48. [PMID: 18000197] http://dx.doi.org/10.1001/jama.298.18.2141

5. Sayer NA, Chiros CE, Sigford B, Scott S, Clothier B, Pickett T, Lew HL. Characteristics and rehabilitation outcomes among patients with blast and other injuries sustained during the Global War on Terror. Arch Phys Med Rehabil. 2008; 89(1):163-70. [PMID: 18164349]

http://dx.doi.org/10.1016/j.apmr.2007.05.025

6. Brustein J. Back from Iraq. Gotham Gazette, 2006;4. 
7. National Coalition for Homeless Veterans. NCHV plan to end homelessness among veterans [Internet]. Washington (DC): National Coalition for Homeless Veterans; 2011. Available from: http://www.nchv.org/page.cfm?id=213

8. Cunningham M. A national commitment to ending homelessness among veterans-Why affordable housing programs matter. Testimony before the U.S. House Committee on Veterans’ Affairs, June 10, 2009 [Internet]. Washington (DC): The Urban Institute; [updated 2009 Jun 10]. Available from: http://www.urban.org/UploadedPDF/ 901263_ending_homelessness_vets.pdf

9. Sayer N, Noorbaloochi S, Frazier P, Carlson K, Gravely A, Murdoch M. Reintegration problems and treatment interests among Iraq and Afghanistan combat veterans receiving VA medical care. Psychiatr Serv. 2010;61(6):589-97. [PMID: 20513682] http://dx.doi.org/10.1176/appi.ps.61.6.589

10. Smith MW, Schnurr PP, Rosenheck RA. Employment outcomes and PTSD symptom severity. Ment Health Serv Res. 2005;7(2):89-101. [PMID: 15974155] http://dx.doi.org/10.1007/s11020-005-3780-2

11. Rosenheck R, Fontana A. A model of homelessness among male veterans of the Vietnam war generation. Am J Psychiatry. 1994;151(3):421-27. [PMID: 8109652]

12. Bullman TA, Kang HK. Posttraumatic stress disorder and the risk of traumatic deaths among Vietnam veterans. J Nerv Ment Dis. 1994;182(11):604-10. [PMID: 7964667] http://dx.doi.org/10.1097/00005053-199411000-00002

13. Freeman T, Roca V. Gun use, attitudes toward violence, and aggression among combat veterans with chronic posttraumatic stress disorder. 2001;189(5):317-20. [PMID: 11379976]

14. Szkudlarek B. Reentry-A review of the literature. Int J Intercultural Relations. 2010;34(1):1-21. http://dx.doi.org/10.1016/j.ijintrel.2009.06.006

15. Hammel J, Magasi S, Heinemann A, Whiteneck G, Bogner J, Rodriguez E. What does participation mean? An insider perspective from people with disabilities. Disabil Rehabil. 2008;30(19):1445-60. [PMID: 18923977]

http://dx.doi.org/10.1080/09638280701625534

16. Magasi S, Hammel J, Heinemann A, Whiteneck G, Bogner J. Participation: A comparative analysis of multiple rehabilitation stakeholders' perspectives. J Rehabil Med. 2009; 41(11):936-44. [PMID: 19841847] http://dx.doi.org/10.2340/16501977-0450

17. Ustun TB, Chatterji S, Bickenbach J, Kostanjsek N, Schneider M. The International Classification of Functioning, Disability and Health: A new tool for understanding disability and health. Disabil Rehabil. 2003;25(11-12):565-71. [PMID: 12959329] http://dx.doi.org/10.1080/0963828031000137063

18. International Classification of Functioning, Disability, and Health. Geneva (Switzerland): World Health Organization; 2001.
19. Whiteneck G. Conceptual models of disability: Past, present, and future. In: Field MJ, Jette AM, Martin L, editors. Workshop on disability in America: A new look. Washington (DC): The National Academies Press; 2006.

20. Jette AM. Physical disablement concepts for physical therapy research and practice. Phys Ther. 1994;74(5):380-86. [PMID: 8171099]

21. Perenboom RJ, Chorus AM. Measuring participation according to the International Classification of Functioning, Disability and Health (ICF). Disabil Rehabil. 2003; 25(11-12):577-87. [PMID: 12959331] http://dx.doi.org/10.1080/0963828031000137081

22. McColl MA, Davies D, Carlson P, Johnston J, Minnes P. The community integration measure: Development and preliminary validation. Arch Phys Med Rehabil. 2001;82(4): 429-34. [PMID: 11295000] http://dx.doi.org/10.1053/apmr.2001.22195

23. Whiteneck GG, Charlifue SW, Gerhart KA, Overholser JD, Richardson GN. Quantifying handicap: A new measure of long-term rehabilitation outcomes. Arch Phys Med Rehabil. 1992;73(6):519-26. [PMID: 1622299]

24. Trigg R, Wood VA. The Subjective Index of Physical and Social Outcome (SIPSO): A new measure for use with stroke patients. Clin Rehabil. 2000;14(3):288-99.

[PMID: 10868724$]$ http://dx.doi.org/10.1191/026921500678119607

25. Resnik L, Plow M, Jette A. Development of the CRIS: A measure of community reintegration of injured services members. J Rehabil Res Dev. 2009;46(4):469-80.

[PMID: 19882482]

http://dx.doi.org/10.1682/JRRD.2008.07.0082

26. Jette AM, Tao W, Haley SM. Blending activity and participation sub-domains of the ICF. Disabil Rehabil. 2007; 29(22):1742-50. [PMID: 17852234] http://dx.doi.org/10.1080/09638280601164790

27. Schuntermann MF. The implementation of the International Classification of Functioning, Disability and Health in Germany: Experiences and problems. Int J Rehabil Res. 2005;28(2):93-102. [PMID: 15900178] http://dx.doi.org/10.1097/00004356-200506000-00001

28. McColl MA, Carlson P, Johnston J, Minnes P, Shue K, Davies D, Karlovits T. The definition of community integration: Perspectives of people with brain injuries. Brain Inj. 1998;12(1):15-30. [PMID: 9483334] http://dx.doi.org/10.1080/026990598122827

29. Cardol M, Brandsma JW, De Groot IJ, Van den Bos GA, De Haan RJ, De Jong BA. Handicap questionnaires: What do they assess? Disabil Rehabil. 1999;21(3):97-105. [PMID: 10206348] http://dx.doi.org/10.1080/096382899297819

30. Cicerone KD, Mott T, Azulay J, Friel JC. Community integration and satisfaction with functioning after intensive cognitive rehabilitation for traumatic brain injury. Arch Phys 
RESNIK et al. Issues in defining and measuring veteran community reintegration

Med Rehabil. 2004;85(6):943-50. [PMID: 15179648]

http://dx.doi.org/10.1016/j.apmr.2003.07.019

31. Johnston M, Nissim EN, Wood K, Hwang K, Tulsky D. Objective and subjective handicap following spinal cord injury: Interrelationships and predictors. J Spinal Cord Med. 2002;25(1):11-22. [PMID: 11939460]

32. Willer B, Ottenbacher KJ, Coad ML. The community integration questionnaire. A comparative examination. Am J Phys Med Rehabil. 1994;73(2):103-11. [PMID: 814099] http://dx.doi.org/10.1097/00002060-199404000-00006

33. Noreau L, Fougeyrollas P, Vincent C. The LIFE-H: Assessment of the quality of social participation. Technol Disabil. 2002;14(3):113-18.

34. Brown M, Dijkers MP, Gordon WA, Ashman T, Charatz H, Cheng Z. Participation objective, participation subjective: A measure of participation combining outsider and insider perspectives. J Head Trauma Rehabil. 2004;19(6):459-81. [PMID: 15602309] http://dx.doi.org/10.1097/00001199-200411000-00004

35. Fougeyrollas P, Noreau L, Bergeron H, Cloutier R, Dion SA, St-Michel G. Social consequences of long term impairments and disabilities: Conceptual approach and assessment of handicap. Int J Rehabil Res. 1998;21(2):127-41. [PMID: 9924676] http://dx.doi.org/10.1097/00004356-199806000-00002

36. Cardol M, De Haan RJ, Van den Bos GA, De Jong BA, De Groot IJ. The development of a handicap assessment questionnaire: The Impact on Participation and Autonomy (IPA). Clin Rehabil. 1999;13(5):411-19. [PMID: 10498348] http://dx.doi.org/10.1191/026921599668601325

37. Brown M. Perspectives on outcome: What disability insiders and outsiders each bring to the assessment table. Arch Phys Med Rehabil. 2009;90(11 Suppl):S36-40. [PMID: 19892073] http://dx.doi.org/10.1016/j.apmr.2009.04.024

38. Cella D, Yount S, Rothrock N, Gershon R, Cook K, Reeve B, Ader D, Fries JF, Bruce B, Rose M; PROMIS Cooperative Group. The Patient-Reported Outcomes Measurement Information System (PROMIS): Progress of an NIH Roadmap cooperative group during its first two years. Med Care. 2007;45(5 Suppl):S3-S11. [PMID: 17443116] http://dx.doi.org/10.1097/01.mlr.0000258615.42478.55

39. Whiteneck GG, Harrison-Felix CL, Mellick DC, Brooks CA, Charlifue SB, Gerhart KA. Quantifying environmental factors: A measure of physical, attitudinal, service, productivity, and policy barriers. Arch Phys Med Rehabil. 2004; 85(8):1324-35. [PMID: 15295760] http://dx.doi.org/10.1016/j.apmr.2003.09.027

40. Khan F, Pallant JF. Use of International Classification of Functioning, Disability and Health (ICF) to describe patient-reported disability in multiple sclerosis and identification of relevant environmental factors. J Rehabil Med.
2007;39(1):63-70. [PMID: 17225040]

http://dx.doi.org/10.2340/16501977-0002

41. President's New Freedom Commission on Mental Health. Achieving the promise: Transforming mental health care in America. Rockville (MD): President's New Freedom Commission on Mental Health; 2003.

42. VA Handbook 1160.01: Uniform mental health services in VA medical centers and clinics. Washington (DC): Department of Veterans Affairs; 2008. Available from: http://www1.va.gov/ vhapublications/ViewPublication.asp?pub_ID=1762

43. Cieza A, Ewert T, Ustün TB, Chatterji S, Kostanjsek N, Stucki G. Development of ICF core sets for patients with chronic conditions. J Rehabil Med. 2004;44 Suppl:9-11. [PMID: 15370742]

44. Stucki A, Cieza A, Michel F, Stucki G, Bentley A, Culebras A, Tufik S, Kotchabhakdi N, Ustun B, Partinen M. Developing ICF core sets for persons with sleep disorders based on the International Classification of Functioning, Disability and Health. Sleep Med. 2008;9(2):191-98.

[PMID: 17644416] http://dx.doi.org/10.1016/j.sleep.2007.01.019

45. Tschiesner U, Cieza A, Rogers SN, Piccirillo J, Funk G, Stucki G, Berghaus A. Developing core sets for patients with head and neck cancer based on the International Classification of Functioning, Disability and Health (ICF). Eur Arch Otorhinolaryngol. 2007;264(10):1215-22.

[PMID: 17569071]

http://dx.doi.org/10.1007/s00405-007-0335-8

46. Vieta E, Cieza A, Stucki G, Chatterji S, Nieto M, SánchezMoreno J, Jaeger J, Grunze H, Ayuso-Mateos JL. Developing core sets for persons with bipolar disorder based on the International Classification of Functioning, Disability and Health. Bipolar Disord. 2007;9(1-2):16-24. [PMID: 17391346] http://dx.doi.org/10.1111/j.1399-5618.2007.00322.x

47. Biering-Sørensen F, Scheuringer M, Baumberger M, Charlifue SW, Post MW, Montero F, Kostanjsek N, Stucki G. Developing core sets for persons with spinal cord injuries based on the International Classification of Functioning, Disability and Health as a way to specify functioning. Spinal Cord. 2006;44(9):541-46. [PMID: 16955074] http://dx.doi.org/10.1038/sj.sc.3101918

48. Kesselring J, Coenen M, Cieza A, Thompson A, Kostanjsek N, Stucki G. Developing the ICF core sets for multiple sclerosis to specify functioning. Mult Scler. 2008;14(2): 252-54. [PMID: 17986511] http://dx.doi.org/10.1177/1352458507082615

49. Geyh S, Cieza A, Schouten J, Dickson H, Frommelt P, Omar Z, Kostanjsek N, Ring H, Stucki G. ICF core sets for stroke. J Rehabil Med. 2004;44 Suppl:135-41.

[PMID: 15370761] http://dx.doi.org/10.1080/16501960410016776

50. Cieza A, Chatterji S, Andersen C, Cantista P, Herceg M, Melvin J, Stucki G, De Bie R. ICF core sets for depression. 
J Rehabil Med. 2004;44 Suppl:128-34. [PMID: 15370760] http://dx.doi.org/10.1080/16501960410016055

51. Stucki A, Daansen P, Fuessl M, Cieza A, Huber E, Atkinson R, Kostanjsek N, Stucki G, Ruof J. ICF core sets for obesity. J Rehabil Med. 2004;44 Suppl:107-13.

[PMID: 15370757]

http://dx.doi.org/10.1080/16501960410016064

52. Resnik L, Plow MA. Measuring participation as defined by the International Classification of Functioning, Disability and Health: An evaluation of existing measures. Arch Phys Med Rehabil. 2009;90(5):856-66. [PMID: 19406308]

http://dx.doi.org/10.1016/j.apmr.2008.11.010

53. Sackett D, Strauss S, Richardson W. Evidence-based medicine: How to practice and teach EBM. New York (NY): Churchill Livingstone; 2000.

54. Haley SM, Fragala-Pinkham MA. Interpreting change scores of tests and measures used in physical therapy. Phys Ther. 2006;86(5):735-43. [PMID: 16649896]

55. Hooley JM. Expressed emotion and relapse of psychopathology. Annu Rev Clin Psychol. 2007;3:329-52.

[PMID: 17716059] http://dx.doi.org/10.1146/annurev.clinpsy.2.022305.095236

56. Kolakowsky-Hayner SA, Miner KD, Kreutzer JS. Longterm life quality and family needs after traumatic brain injury. J Head Trauma Rehabil. 2001;16(4):374-85.

[PMID: 11461659] http://dx.doi.org/10.1097/00001199-200108000-00007

57. Kreuter M. Spinal cord injury and partner relationships. Spinal Cord. 2000;38(1):2-6. [PMID: 10762191] http://dx.doi.org/10.1038/sj.sc.3100933

58. Schooler N, Hogarty GE, Weissman MM. Social Adjustment Scale II. In: Hargraves WA, Atkinson CC, Sorenson JE, editors. Resource materials for community mental health programs. Washington (DC): U.S. Government Printing Office; 1979.

59. Falloon IR, Boyd JL, McGill CW. Family care of schizophrenia: A problem-solving approach to the treatment of mental illness. New York (NY): Guilford Press; 1984.

60. McFarlane WR. Multiple-family groups and psychoeducation in the treatment of schizophrenia. New Dir Ment Health Serv. 1994;62:13-22. [PMID: 7935283$]$ http://dx.doi.org/10.1002/yd.23319946204
61. McFarlane WR, Link B, Dushay R, Marchal J, Crilly J. Psychoeducational multiple family groups: Four-year relapse outcome in schizophrenia. Fam Process. 1995; 34(2):127-44. [PMID: 7589414] http://dx.doi.org/10.1111/j.1545-5300.1995.00127.x

62. Miklowitz DJ, George EL, Richards JA, Simoneau TL, Suddath RL. A randomized study of family-focused psychoeducation and pharmacotherapy in the outpatient management of bipolar disorder. Arch Gen Psychiatry. 2003;60(9):904-12.

[PMID: 12963672] http://dx.doi.org/10.1001/archpsyc.60.9.904

63. Miklowitz DJ, Simoneau TL, George EL, Richards JA, Kalbag A, Sachs-Ericsson N, Suddath R. Family-focused treatment of bipolar disorder: 1-year effects of a psychoeducational program in conjunction with pharmacotherapy. Biol Psychiatry. 2000;48(6):582-92. [PMID: 11018229] http://dx.doi.org/10.1016/S0006-3223(00)00931-8

64. Rivera PA, Elliott TR, Berry JW, Grant JS. Problem-solving training for family caregivers of persons with traumatic brain injuries: A randomized controlled trial. Arch Phys Med Rehabil. 2008;89(5):931-41. [PMID: 18452743] http://dx.doi.org/10.1016/j.apmr.2007.12.032

Submitted for publication June 1, 2010. Accepted in revised form January 10, 2011.

This article and any supplementary material should be cited as follows:

Resnik L, Bradford DW, Glynn SM, Jette AM, Johnson Hernandez C, Wills S. Issues in defining and measuring veteran community reintegration: Proceedings of the Working Group on Community Reintegration, VA Rehabilitation Outcomes Conference, Miami, Florida. J Rehabil Res Dev. 2012;49(1):87-100.

http://dx.doi.org/10.1682/JRRD.2010.06.0107

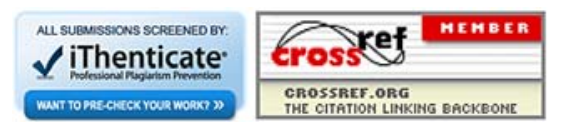

